Article

\title{
Estimation of the Effect of Soil Texture on Nitrate-Nitrogen Content in Groundwater Using Optical Remote Sensing
}

\section{Yongyoot Witheetrirong ${ }^{1}$, Nitin Kumar Tripathi ${ }^{1, *}$, Taravudh Tipdecho ${ }^{1}$ and Preeda Parkpian ${ }^{2}$}

1 Remote Sensing and GIS Field of Study, School of Engineering and Technology, Asian Institute of Technology, P.O. Box 4, Klong Luang, Pathumthani 12120, Thailand;

E-Mails: st103527@ait.ac.th (Y.W.); taravudh@ait.ac.th (T.T.)

2 Environmental Engineering and Management, School of Environment, Resources and Development, Asian Institute of Technology, P.O. Box 4, Klong Luang, Pathumthani 12120, Thailand;

E-Mail: preeda@ait.ac.th

* Author to whom correspondence should be addressed; E-Mail: nitinkt@ait.ac.th;

Tel.: +66-2524-5799; Fax: +66-2524-5597.

Received: 27 May 2011; in revised form: 22 July 2011 / Accepted: 5 August 2011 /

Published: 19 August 2011

\begin{abstract}
The use of chemical fertilizers in Thailand increased exponentially by more than 100-fold from 1961 to 2004. Intensification of agricultural production causes several potential risks to water supplies, especially nitrate-nitrogen $\left(\mathrm{NO}_{3}{ }^{-}-\mathrm{N}\right)$ pollution. Nitrate is considered a potential pollutant because its excess application can move into streams by runoff and into groundwater by leaching. The nitrate concentration in groundwater increases more than 3-fold times after fertilization and it contaminates groundwater as a result of the application of excess fertilizers for a long time. Soil texture refers to the relative proportion of particles of various sizes in a given soil and it affects the water permeability or percolation rate of a soil. Coarser soils have less retention than finer soils, which in the case of $\mathrm{NO}_{3}{ }^{-}-\mathrm{N}$ allows it to leach into groundwater faster, so there is positive relationship between the percentage of sands and $\mathrm{NO}_{3}{ }^{-} \mathrm{N}$ concentration in groundwater wells. This study aimed to estimate the effect of soil texture on $\mathrm{NO}_{3}{ }^{-}-\mathrm{N}$ content in groundwater. Optical reflectance data obtained by remote sensing was used in this study. Our hypothesis was that the quantity of nitrogen leached into groundwater through loam was higher than through clay. Nakhon Pathom province, Thailand, was selected as a study area where the terrain is mostly represented by a flat topography. It was found that classified LANDSAT images delineated paddy fields as covering $29.4 \%$ of the study area, while sugarcane covered
\end{abstract}


$10.4 \%$, and $60.2 \%$ was represented by "others". The reason for this classified landuse was to determine additional factors, such as vegetation, which might directly affect the quantity of $\mathrm{NO}_{3}{ }^{-} \mathrm{N}$ in soil. Ideally, bare soil would be used as a test site, but in fact, no such places were available in Thailand. This led to an indirect method to estimate $\mathrm{NO}_{3}{ }^{-} \mathrm{N}$ on various soil textures. Through experimentation, it was found that $\mathrm{NO}_{3}{ }^{-} \mathrm{N}$ measured through the loam in sugarcane $(\mathrm{I}=0.0054, \mathrm{p}<0.05)$ was lower than clay represented by paddies $(\mathrm{I}=0.0305, \mathrm{p}<0.05)$. This had a significant negative impact on the assumption. According to the research and local statistical data, farmers have always applied an excess quantity of fertilizer on paddy fields. This is the main reason for the higher quantity of $\mathrm{NO}_{3}{ }^{-} \mathrm{N}$ found in clay than loam in this study. This case might be an exceptional study in terms of quantity of fertilizers applied to agricultural fields.

Keywords: groundwater; spatial autocorrelation; soil texture; Geographic Information Systems (GIS); nitrates; remote sensing

\section{Introduction}

Existing increasing demands for agricultural products are driven by the growing World population and economic growth. Intensification of agricultural production causes several potential risks to water supplies. Nutrients from chemical fertilizers are more immediately available for plant uptake than in manure, but they may also be more easily leached into groundwater if used in excess [1]. The use of chemical fertilizers in Thailand started to increase exponentially, increasing more than 100-fold from 18,000 tons in 1961 to $2,000,000$ tons in 2004 , but in spite of this massive increase in chemical fertilizer use, the yields of rice and maize have hardly increased. This suggests a tremendous loss of fertilizers into the environment due to their imbalanced use and poor management [2].

Nitrate-nitrogen $\left(\mathrm{NO}_{3}{ }^{-} \mathrm{N}\right)$, which is an essential source of nitrogen $(\mathrm{N})$ for plant growth, is now also considered a potential pollutant by the U.S. Environmental Protection Agency (EPA) [3]. This is because excess applied amounts of $\mathrm{NO}_{3}{ }^{-} \mathrm{N}$ can move into streams by runoff and into groundwater by leaching, thereby becoming an environmental hazard [4]. Many of the major sources of nitrate come from the use and production of fertilizers and waste materials, which are anthropogenic sources of nitrate contamination of groundwater [5]. Although nitrogen exists in many forms, nitrate is the most available form to plants [6]. Nitrate is very soluble in water, and it is readily carried to plant roots as the crop uses water. Soil nitrate unused during the growing season is free to move with water that percolates through the soil. This nitrate has the potential to contaminate groundwater if the water percolates beyond the root zone [7]. $\mathrm{NO}_{3}{ }^{-}-\mathrm{N}$ is a problem as a contaminant in drinking water, primarily from groundwater and wells, due to its harmful biological effects [8]. The determining factor in the WHO's decision to set the Maximum Contaminant Levels (MCLs) at $10 \mathrm{mg} / \mathrm{L}$ for the safety limit of drinking water [9], and it was the occurrence of methemoglobinemia in infants under six months [1]. Although the Maximum Contaminant Level for nitrogen was set at $10 \mathrm{mg} / \mathrm{L}$ nitrate-nitrogen, in 1976, EPA suggested that water having concentrations above $1 \mathrm{mg} / \mathrm{L}$ should not be used for infant feeding [10]. 
Groundwater in Thailand is a source of household drinking water and supplements surface water for agriculture and livestock uses. Groundwater is used for the public water supply in $20 \%$ of the nation's towns and cities and for half of the sanitary districts. It is estimated that $75 \%$ of domestic water is obtained from groundwater sources, and that they serve some 35 million people in villages and in urban areas [1]. The nitrate concentration in the groundwater increased more than three times after fertilization, from $1.8 \mathrm{mg} / \mathrm{L}$ to $7.2 \mathrm{mg} / \mathrm{L}_{\text {of }} \mathrm{NO}_{3}{ }^{-}-\mathrm{N}$, contamination groundwater due to the application of excess fertilizers which have been applied for long time [11].

Soils have varied retentive properties depending on their texture and organic matter content. Soil texture refers to the relative proportion of particles of various sizes in a given soil. Sandy soils have less retention than finer clay soils because sandy soils have less silt and clay [12], which give rise to a lower cation exchange capacity (CEC) [13], in the case of $\mathrm{NO}_{3}{ }^{-}-\mathrm{N}$ allows it to leach into groundwater faster, so there is positive relationship between the percentage of sands and $\mathrm{NO}_{3}{ }^{-}-\mathrm{N}$ concentration in groundwater wells [14]. CEC is the sum total of exchangeable cations that a soil can absorb. Although $\mathrm{NO}_{3}{ }^{-} \mathrm{N}$ is an anion that can readily leach through the soil profile, soils with significant quantities of silt, clay, and organic matter will also retain more $\mathrm{NO}_{3}{ }^{-} \mathrm{N}$ than soils without much silt and clay. Soil texture also affects water permeability or percolation rate of a soil. Smaller amounts of silt and clay have higher water permeability rates than loamy sands or sandy loams [4].

Remote sensing has the general advantage of providing spatially distributed measurements on a temporal basis. However, it mostly observes the surface of the Earth. There are also below ground remote sensing applications in fields such as geology, hydrogeology, mineralogy, etc. Therefore, a link must be established between the surface observation and the subsurface (groundwater) phenomena. Physical features of the landscape such as alignments are detected in satellite images, and these provide valuable information for groundwater investigations [15]. Aerial photography and visible and near-infrared satellite observations are widely used in groundwater exploration [16-18]. Spectral reflectance will be related with nitrate content in groundwater by indirect relationships.

The hypothesis presented herein is the fact that the quantity of nitrate nitrogen accumulated in groundwater through leaching by loam textured soils is higher than that of clay textured ones. This study aimed to estimate the effect of soil texture on $\mathrm{NO}_{3}{ }^{-}-\mathrm{N}$ content in groundwater. Optical reflectance data obtained by remote sensing was used in this study.

\section{Materials and Methods}

\subsection{Data Preparation}

The study site is Nakhon Pathom province in Thailand (Figure 1) which is one of the monitoring provinces for land subsidence of Bangkok and vicinities. The province is divided into seven administrative districts. Most of the area are plains with no mountainous land. Plateaus are found in the west of Amphoe Muang and Amphoe Kamphaeng Saen. The plains are found along the Tha Cheen River. The study covers an area of 2,168 square kilometers, and an area of about $50 \%$ of this fertile land is mainly devoted to rice and fruit crops, and $8.16 \%$ is sugarcane[19], thus most of the residents earn their living from agriculture. 
Figure 1. Study area in Nakhon Pathom province, Thailand.

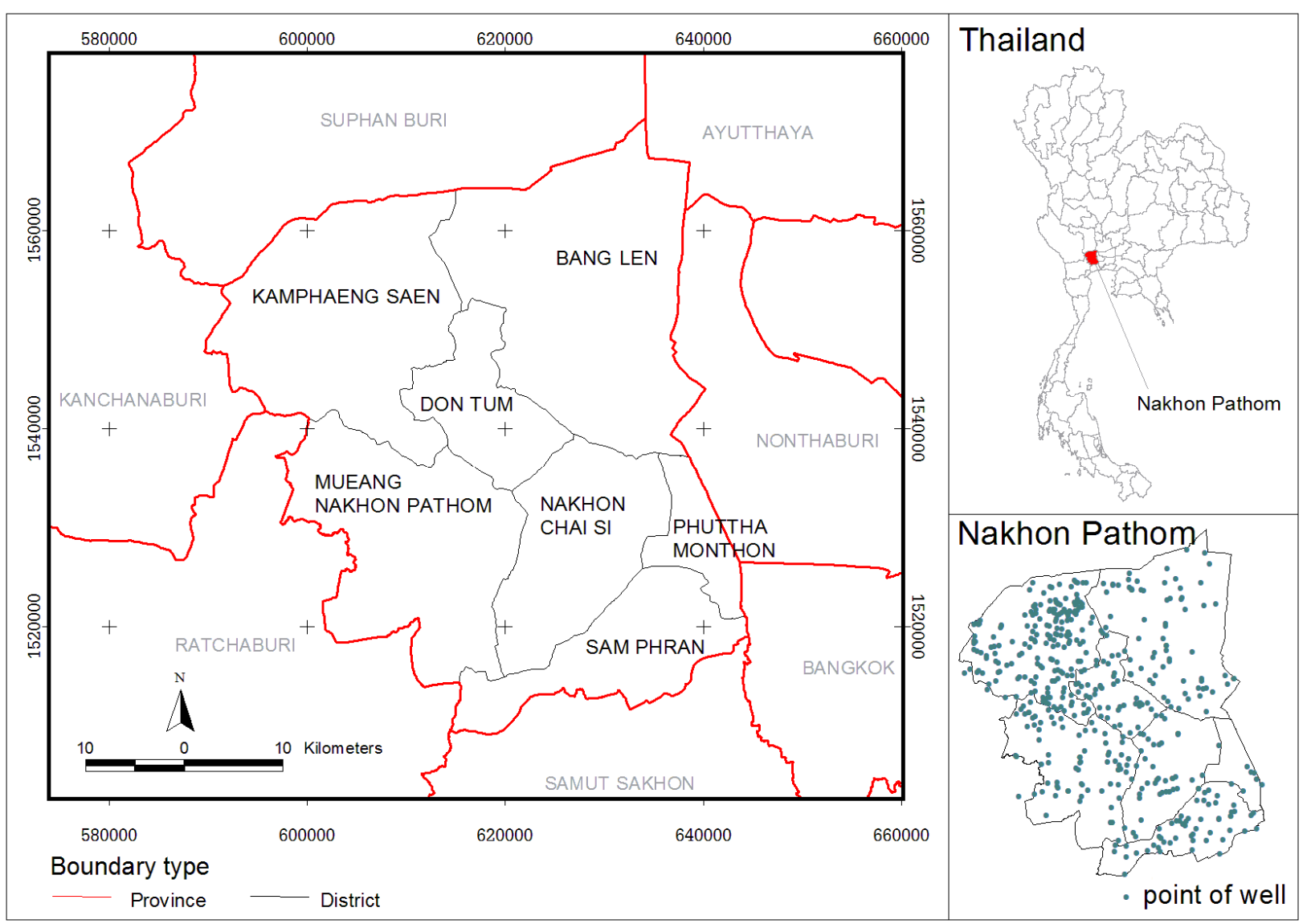

LANDSAT TM-5 images acquired on 14 May 2010, scene center location (lat/long: 13.917, 100.100), were used to classify for landuse and extract the spectral reflectance. Groundwater analysis data was collected in May 2010 from 32 monitoring stations operated by the Department of Groundwater Resources (DGR). The spatial data layers such as soil unit and geology were provided by the Geo-Informatics and Space Technology Development Agency (GISTDA). The analysis of groundwater properties were derived from secondary data obtained from DGR. Several interpolations were implemented and then the most suitable results was used in the study. Soil texture and soil $\mathrm{pH}$ layers were reclassified from soil properties of the top soil layer.

\subsection{Data Interpolation}

Nitrate content $\left(\mathrm{NO}_{3}{ }^{-}-\mathrm{N}\right)$ from 32 monitor wells were converted to raster data by several interpolation methods in ArcView GIS (extension: Spatial analyst by ESRI and Kriging interpolation), such as IDW, Spline, and Kriging. The most suitable result for this study was selected by accuracy checking from each interpolation method. The extraction of grid value under the point includes checking points were provided. The details of each criterion are Inverse Distance Weighted (IDW) with $\mathrm{p}=2$; known as the inverse distance squared weighted interpolation, Spline: Weight $(\mathrm{W})=0.1$, 0.5; Regular (R), Tension (T), Kriging: Spherical, Circular, Exponential, Gaussian, Linear, Universal1 (linear with linear drift), and Universal2 (linear with quadratic drift). 


\subsection{Spatial Autocorrelation Analysis}

The interpolation results were analyzed by Spatial Autocorrelation Analysis. Initially, Moran's I was used to assess global autocorrelation of the nitrate concentrations for the methods of analysis. Values of Moran's I less than 0 indicated a negative spatial autocorrelation, i.e., clustering of dissimilar values, while those greater than 0 indicated positive spatial clustering, that is, clustering of similar values in similar areas [20]. For the interpolated concentration of $\mathrm{NO}_{3}{ }^{-}-\mathrm{N}$ result which is a freeform polygon analysis, a binary weight matrix was created, using Queen Contiguity, identifying which areas were considered neighbors. This method takes into account those areas that share edges to the immediate left, right, up, and down as well as taking diagonal edges into account (reflecting how a queen moves in a game of chess). In this matrix, a " 1 " was assigned if location $i$ was the neighboring location $j$, otherwise a zero was assigned [21]. All spatial autocorrelation analyses were performed using the GeoDa software.

\subsection{Spectral Extraction Analysis}

$\mathrm{NO}_{3}{ }^{-}-\mathrm{N}$ that was obtained from Spatial Autocorrelation Analysis was defined as an input for further Spectral Extraction Analysis that incorporated soil texture, soil $\mathrm{pH}$, and landuse. The spectral reflectance related to soil texture, soil $\mathrm{pH}$, and landuse were analyzed.

\subsection{Statistical Analysis}

By interpolation method, statistical analysis (ANOVA and DMRT) were applied to the process of best fit selection based on interpolation technique.

\subsection{Software}

Various software packages, namely ArcView GIS, Spatial analyst by ESRI, Kriging Interpolation Extension 2.01 [22], ENVI, SPSS statistics, and GeoDa, were used in this study.

\section{Results}

\subsection{Data Preparation}

\subsubsection{LANDSAT Imagery Data}

Visual interpretation was used to classify an agricultural main crop in this study. Figure 2 represents LANDSAT image of the samples' rice paddy field and sugarcane areas (Figure 3).

\subsubsection{Soil Texture}

There were only two soil textures: loam (36.7\%) and clay (63.3\%). Soil texture provides a standard terminology related to the relative percentages of sand, silt, and clay. Texture controls the capacity of the soil to attract and bind potential pollutants to individual soil particles. Finer texture soils have the greater capacity to provide exchange sites and thereby bind pollutants, which result in a lower transport potential. Coarser-textured soils function oppositely in that transport potential is higher and 
thereby the risk for ground water contamination is relatively greater [23]. Figure 4 shows that most of the topsoil cover in the study site was covered by clay from the North to South, and loam was found in the Northwest; white color (blank area) means an area which is not available in the soil map.

Figure 2. The false color composite of LANDSAT imagery data (432) of Nakhon Pathom, Thailand.

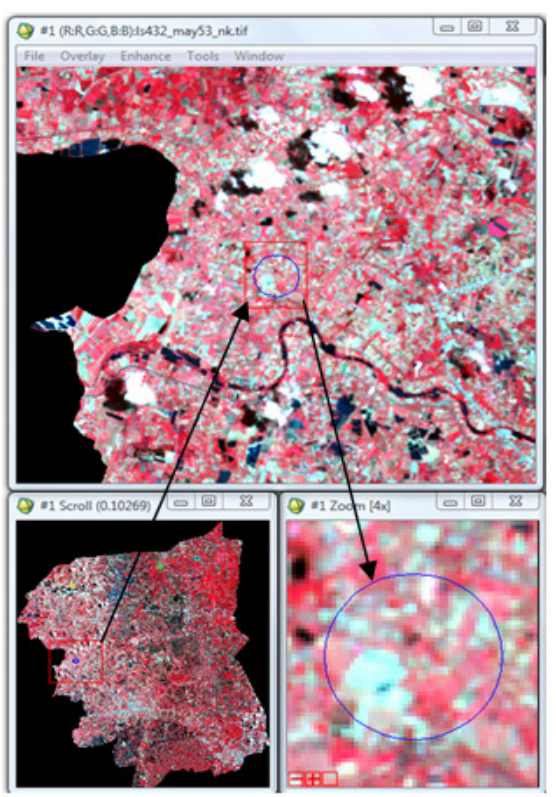

(a)

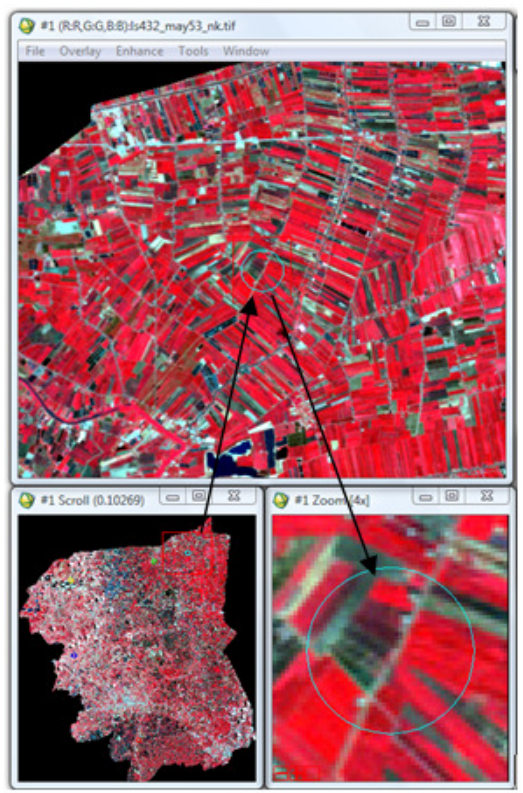

(b)

Figure 3. Main landuses of the study area in Nakhon Pathom in 2010.

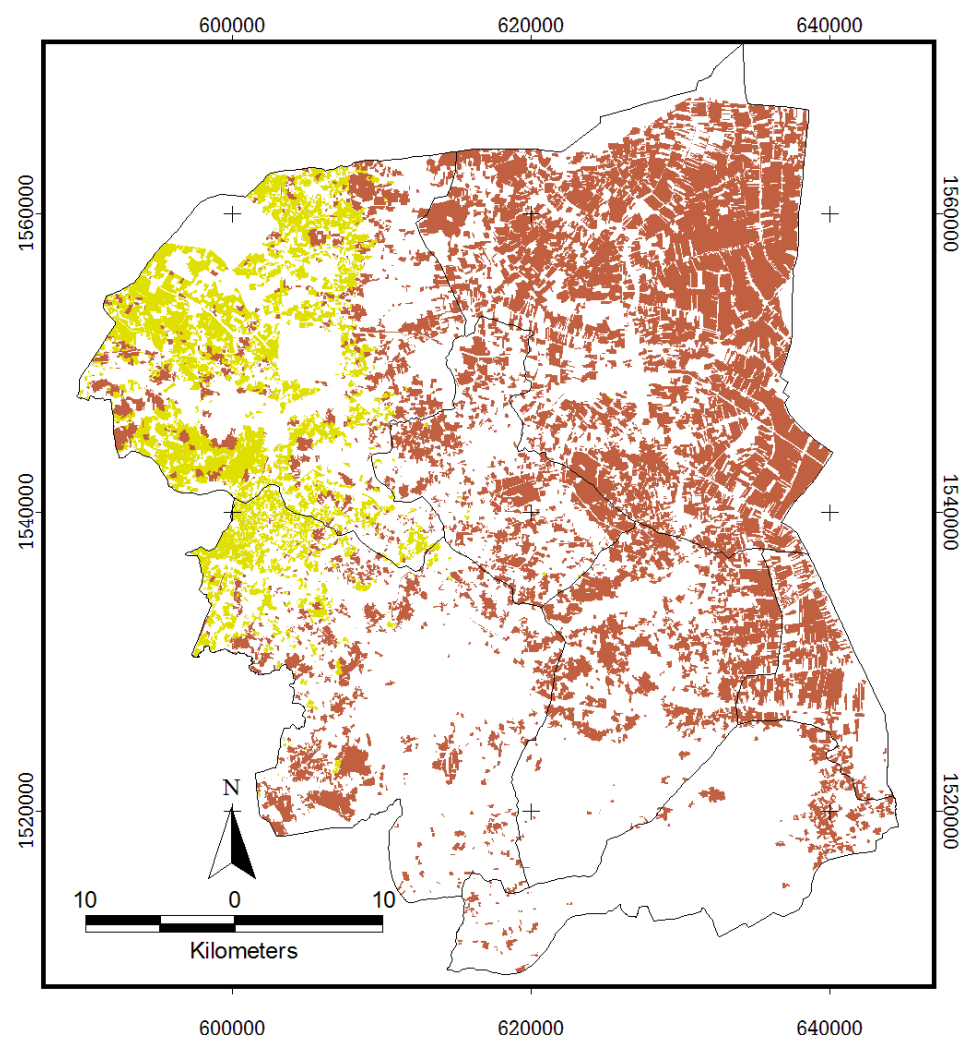

Crop type

$\square$ Political boundary Rice paddy Sugarcane 
Figure 4. Map of soil texture classes in the study site.

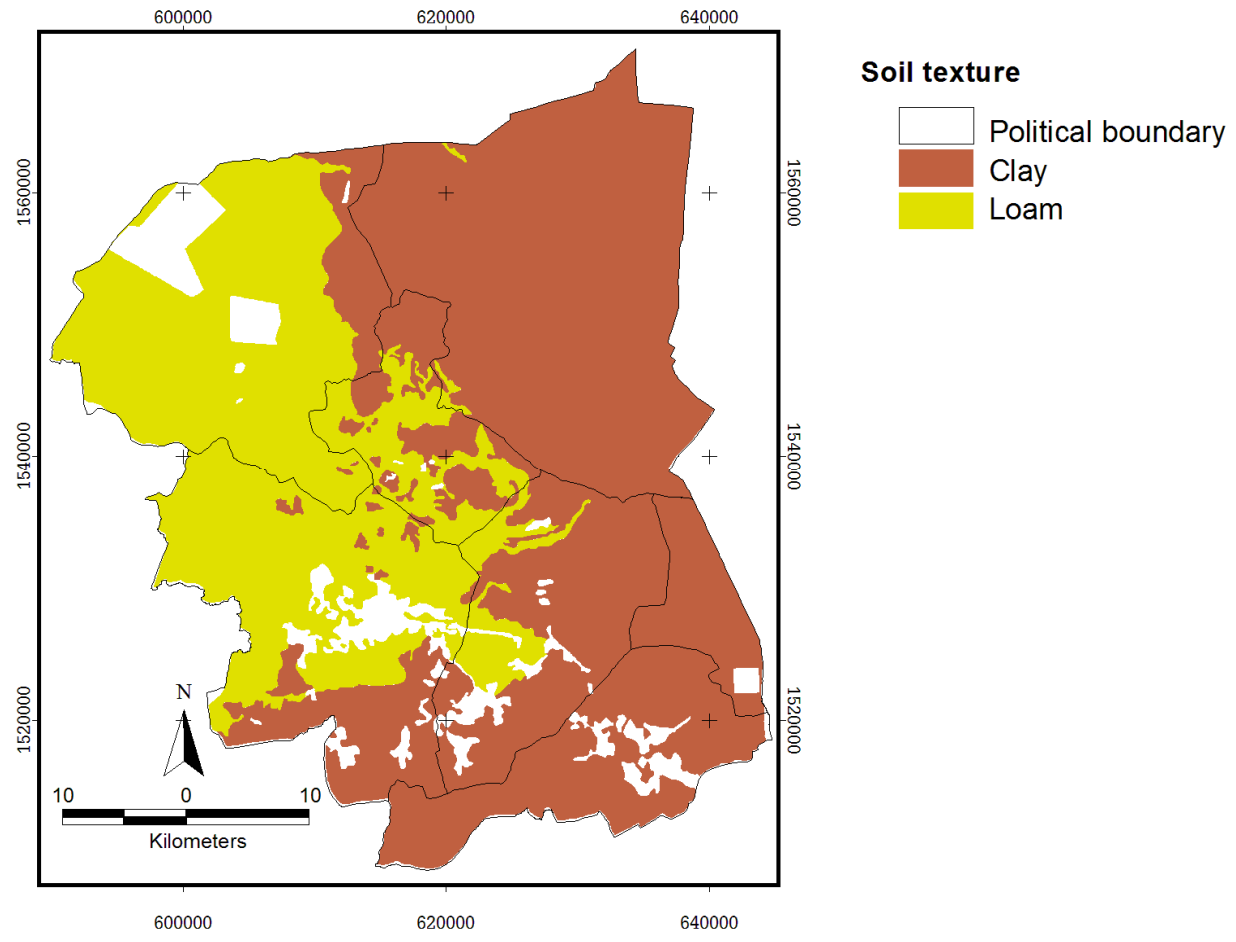

\subsubsection{Soil $\mathrm{pH}$}

For the study of soil series in Thailand, the Land Development Department (LDD) has classified soils into 62 Great Group phases, focusing on the soil suitability related to crop cultivation [24]. A soil $\mathrm{pH}$ map (Figure 5) was generated from the average $\mathrm{pH}$ of the Great Group phases in the study area. The classes of soil $\mathrm{pH}$ which were reclassified are described in Table 1.

Figure 5. Map of soil $\mathrm{pH}$ classes in the study site.

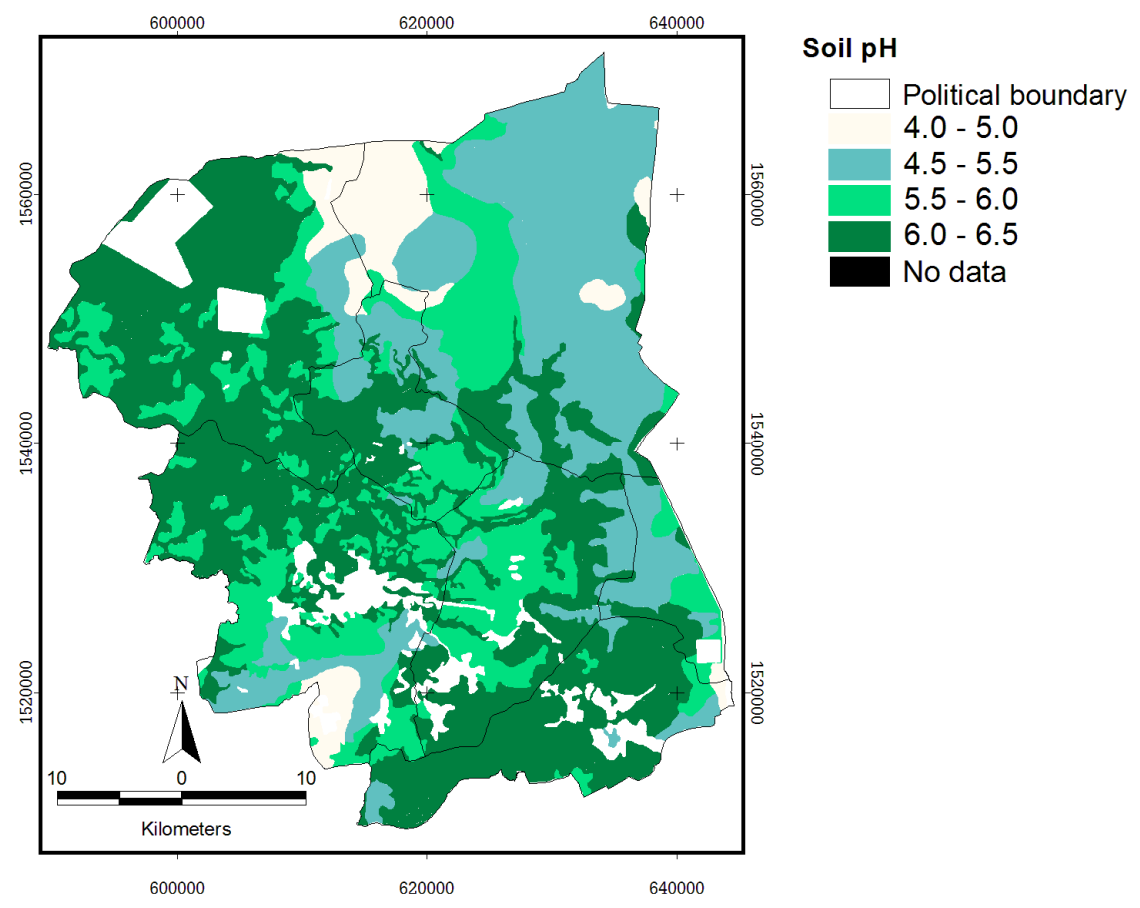


Table 1. The classes of soil $\mathrm{pH}$ reclassified by several soil series.

\begin{tabular}{|c|c|c|c|c|c|c|}
\hline Class & pH range & Group of soil series * & Min & $\operatorname{Max}$ & Average & Area $\left(\mathrm{Km}^{2}\right)$ \\
\hline 1 & $4.0-5.0$ & $11,11 \mathrm{f}$ & 4.0 & 5.0 & 4.5 & 125.32 \\
\hline 2 & $5.0-5.5$ & $2,2 f, 2 / 11$ & 5.0 & 6.0 & 5.5 & 554.83 \\
\hline 3 & $5.5-6.0$ & $1,1 / 2,1 \mathrm{f}, 4,4 / 38$ & 5.5 & 6.5 & 6.0 & 451.94 \\
\hline 4 & $6.0-6.5$ & $3,3 \mathrm{f}, 8,8 / 2,8 / 3,38,38 / 7,38 \mathrm{~B}$ & $\begin{array}{l}5.5 \\
60\end{array}$ & 7.0 & 6.25 & $\begin{array}{l}383.22 \\
47927\end{array}$ \\
\hline
\end{tabular}

* Group of soil series in Thailand [24-26].

\subsubsection{Groundwater Pond}

The study area includes 32 monitoring groundwater ponds, see Figure 6 . The circular area of 500 meters buffered from groundwater ponds represents the sample area of sugarcane (a) and rice paddy (b), the center of each circle is the pond. The randomly selected five points were shown in yellow color with concentration of $\mathrm{NO}_{3}{ }^{-}-\mathrm{N}$ in $\mathrm{mg} / \mathrm{L}$ and the remaining 27 points for interpolation, was shown in blue color.

Figure 6. Location of groundwater wells.

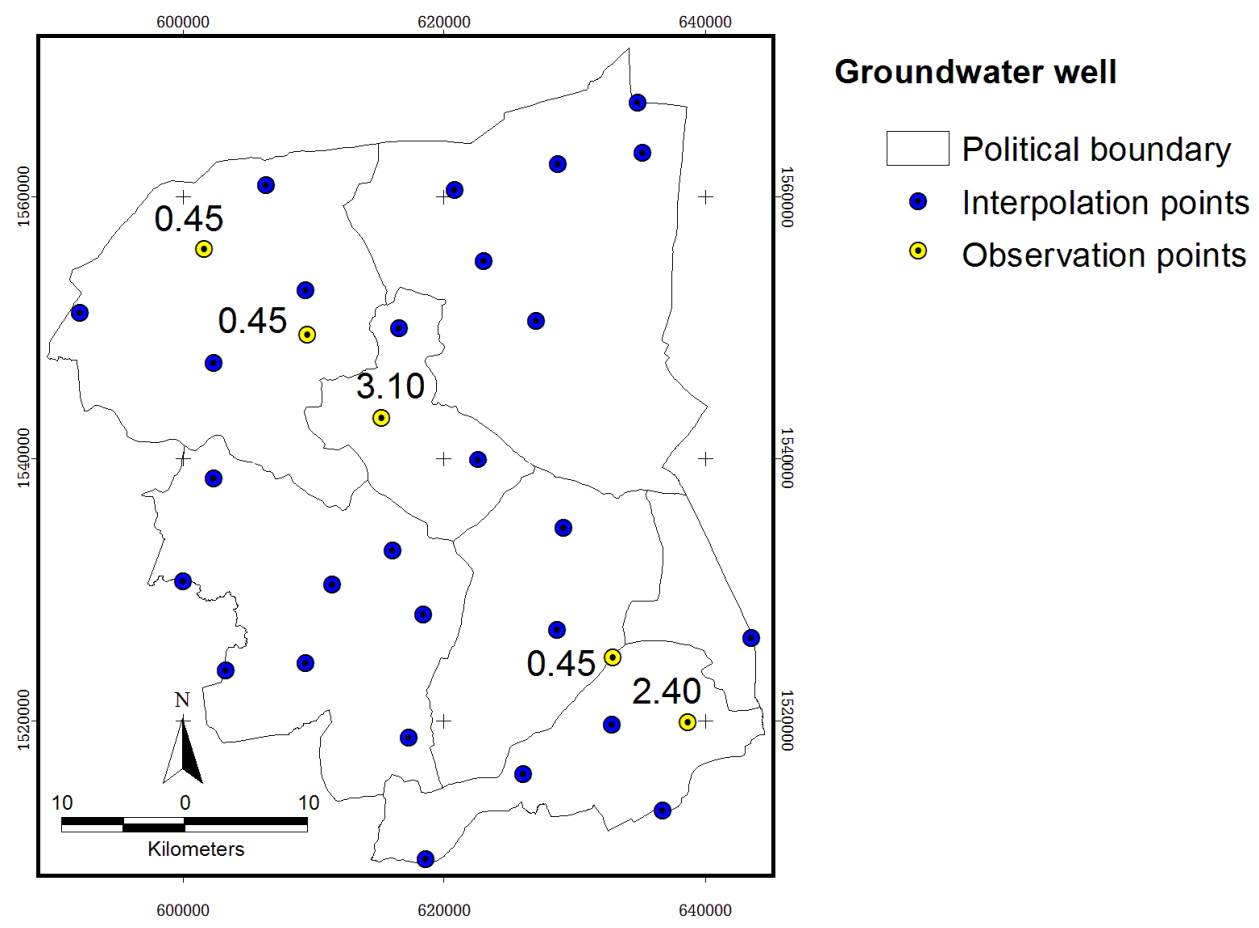

\section{2. $\mathrm{NO}_{3}{ }^{-}-\mathrm{N}$ Interpolation}

The interpolation method results in Figure 7 show several $\mathrm{NO}_{3}{ }^{-} \mathrm{N}$ patterns in the study site. The fixed effects model analysis of variance (ANOVA) [27,28] was used to figure out the most suitable interpolation method across the study area. In Table 2, the interpolation method experiments of $\mathrm{NO}_{3}{ }^{-}-\mathrm{N}$ concentration in Nakhon Pathom province showed that the treatment with KRIG3 of the interpolation methods showed the highest $\mathrm{NO}_{3}{ }^{-}-\mathrm{N}$ concentration in groundwater (1.1013), but KRIG6 showed the lowest (1.0002), while the treatment with Sample $\mathrm{NO}_{3}{ }^{-} \mathrm{N}$ is the observed data (1.0969). 
Figure 7. Surface results from several interpolation methods, darker colors mean higher $\mathrm{NO}_{3}{ }^{-}-\mathrm{N}$ content in groundwater.

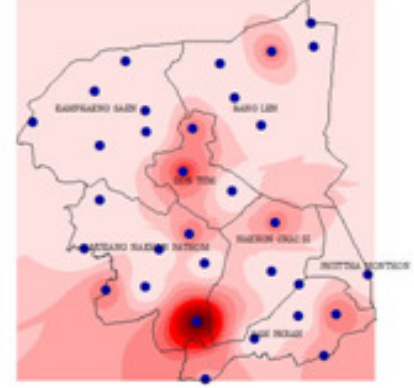

IDW

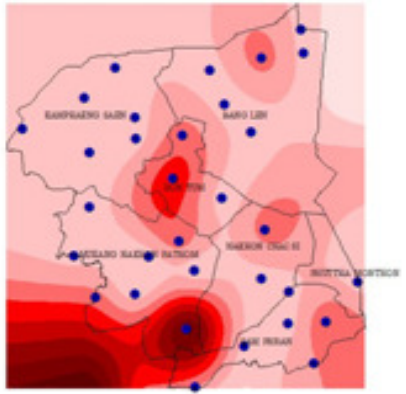

Spline3

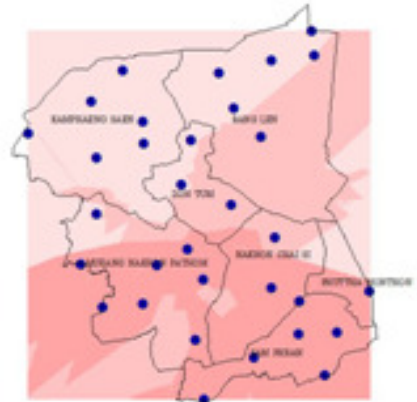

Kriging2

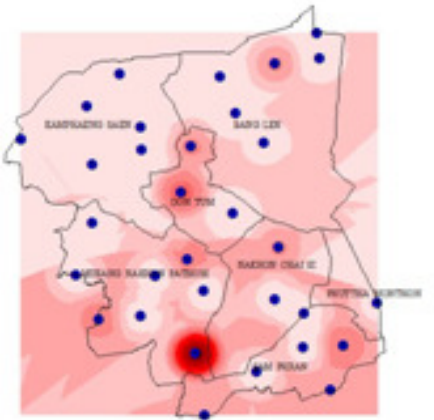

Kriging5

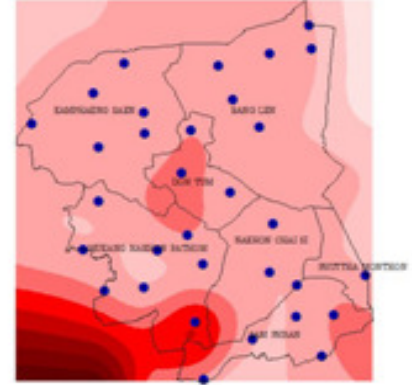

Spline1



Spline4

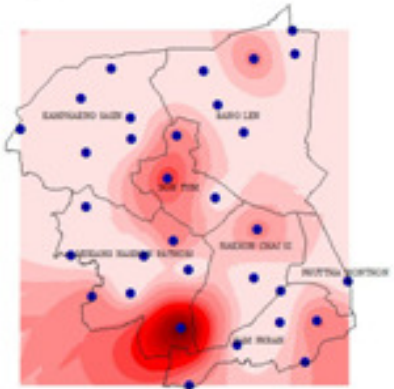

Kriging3

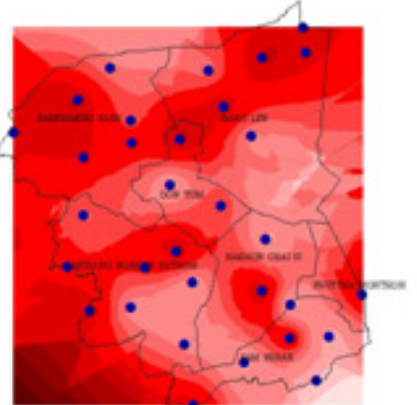

Kriging6

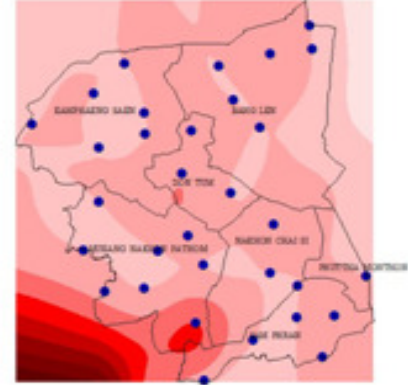

Spline2

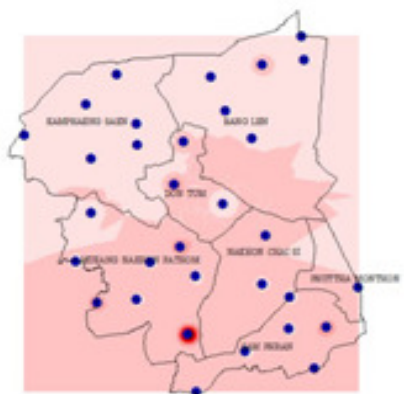

Kriging1



Kriging 4

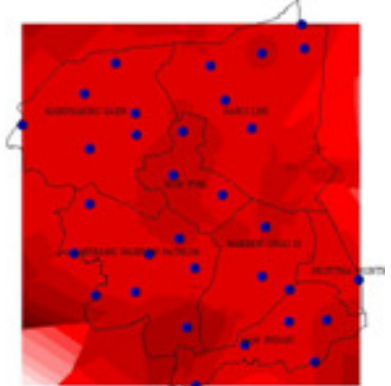

Kriging7

The results from Table 2 show that the $\mathrm{NO}_{3}{ }^{-}-\mathrm{N}$ concentration mean was not significantly different at the 5\% level. The most suitable result, which is the closest mean of an interpolation method to the observed data and KRIG4 as the selected method, was Kriging with Gaussian model (Figure 8). The input data for the Kriging interpolation carried out using a Gaussian model, is $\mathrm{NO}_{3}{ }^{-} \mathrm{N}^{-}$concentration in $\mathrm{mg} / \mathrm{L}$, output cell size $=100 \times 100$ meters, search radius distance $=10,000$ meters, and number of 
neighbors $=12$. The limiting distance was defined based on the results of pattern analysis and the minimum requirements of Kriging interpolation.

Table 2. Average concentration of $\mathrm{NO}_{3}{ }^{-} \mathrm{N}$ varieties in interpolation method.

\begin{tabular}{|c|c|}
\hline Interpolation Methods & $\mathbf{N O}_{3}{ }^{-}-\mathbf{N}$ concentration in groundwater $\left.\mathbf{( m g} / \mathbf{L}\right)$ \\
\hline Observed (Sample $\left.\mathrm{NO}_{3}{ }^{-}-\mathrm{N}\right)$ & 1.0969 \\
IDW1 & 1.0100 \\
SPLINE1 & 1.0577 \\
SPLINE2 & 1.0607 \\
SPLINE3 & 1.0205 \\
SPLINE4 & 1.0205 \\
KRIG1 & 1.1030 \\
KRIG2 & 1.1016 \\
KRIG3 & 1.1032 \\
KRIG4 & 1.1013 \\
KRIG5 & 1.0505 \\
KRIG6 & 1.0002 \\
KRIG7 & 1.0065 \\
F-test & not significant \\
CV $(\%)$ & 87.2370 \\
\hline
\end{tabular}

Figure 8. Nitrate interpolated by Kriging employing Gaussian.

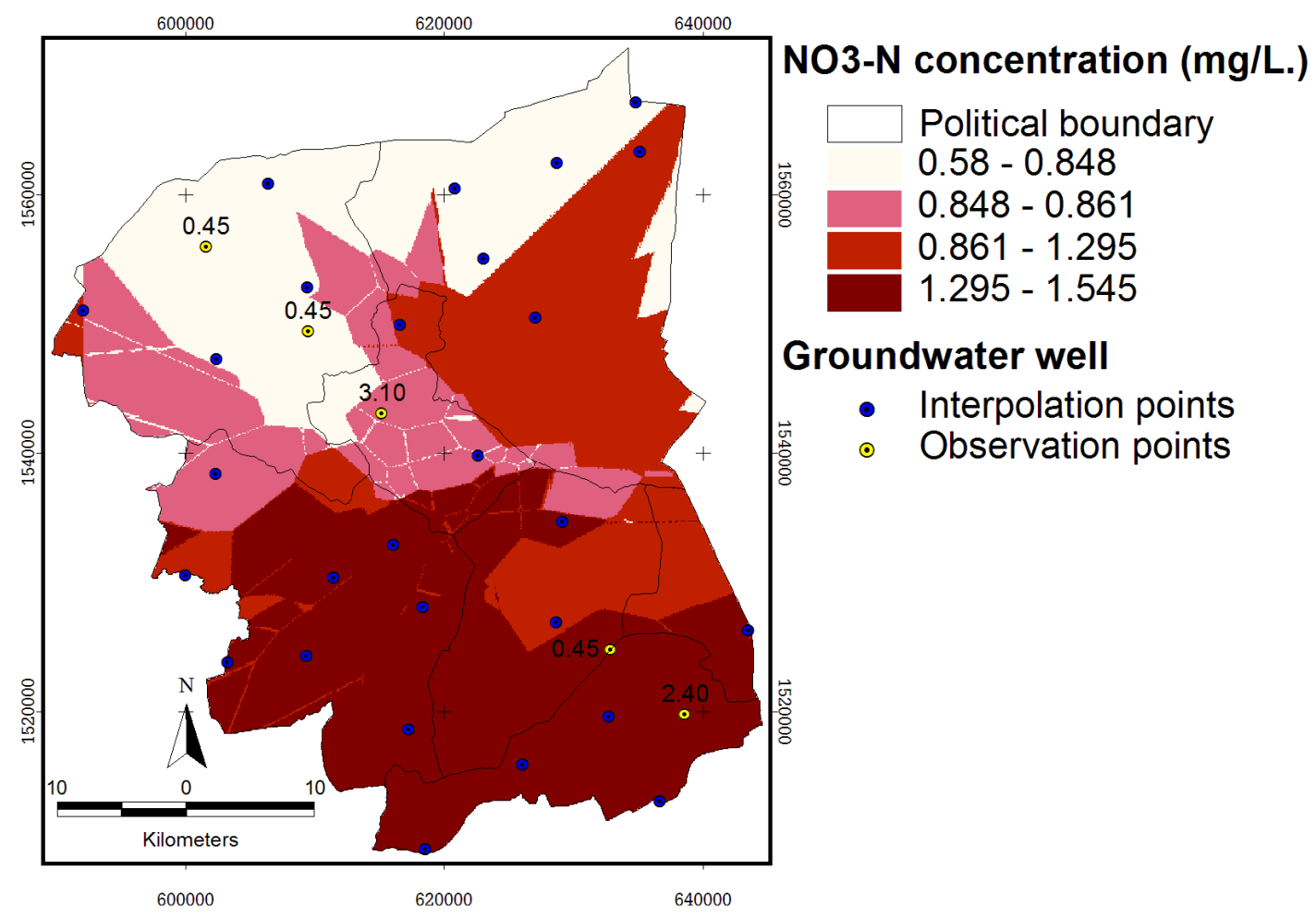




\subsection{Spatial Autocorrelation Analysis}

To process the spatial statistical analysis, the interpolation result surface from the Kriging with Gaussian criteria process was converted from the grid (100 meter grid size) to polygon data layer. Means of each grid value was generated to be the polygon value by reclassification. The result of this analysis is shown in Figure 9.

Figure 9 shows that the results from an analysis of spatial autocorrelation from Kriging interpolation with Gaussian; (a) the analysis for whole study area, the reclassification of the cluster from High-High value and Low-Low value in (b) and (c), respectively. Classes of nitrate with sub-clusters were shown in small letters, so HH-hh means "high-high cluster which was found in High-High from Figure 9 (b)", while on the other hand HH-ll means low-low in High-High.

Figure 9. Spatial autocorrelation analysis of $\mathrm{NO}_{3}{ }^{-}-\mathrm{N}$.
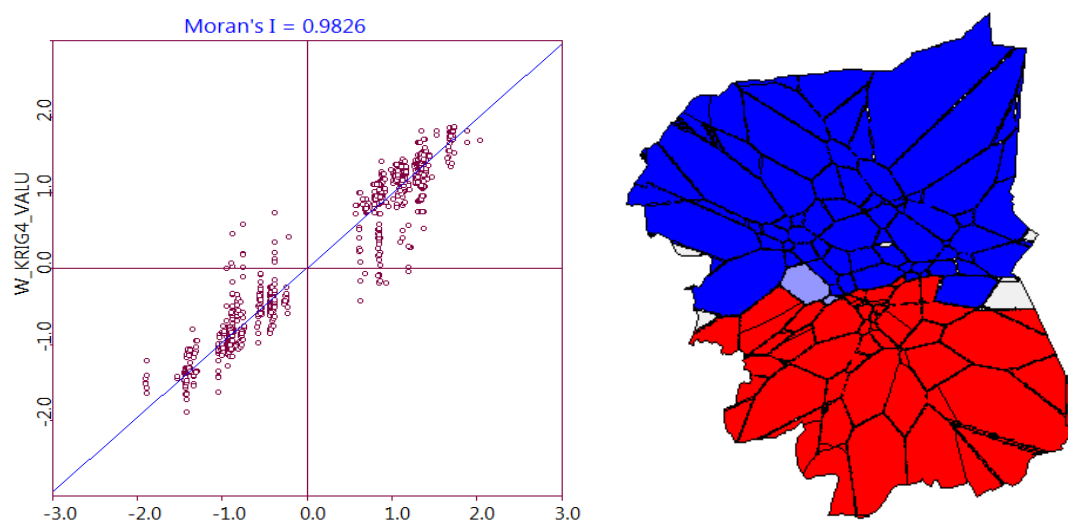

Not Significant

High-High

Low-Low
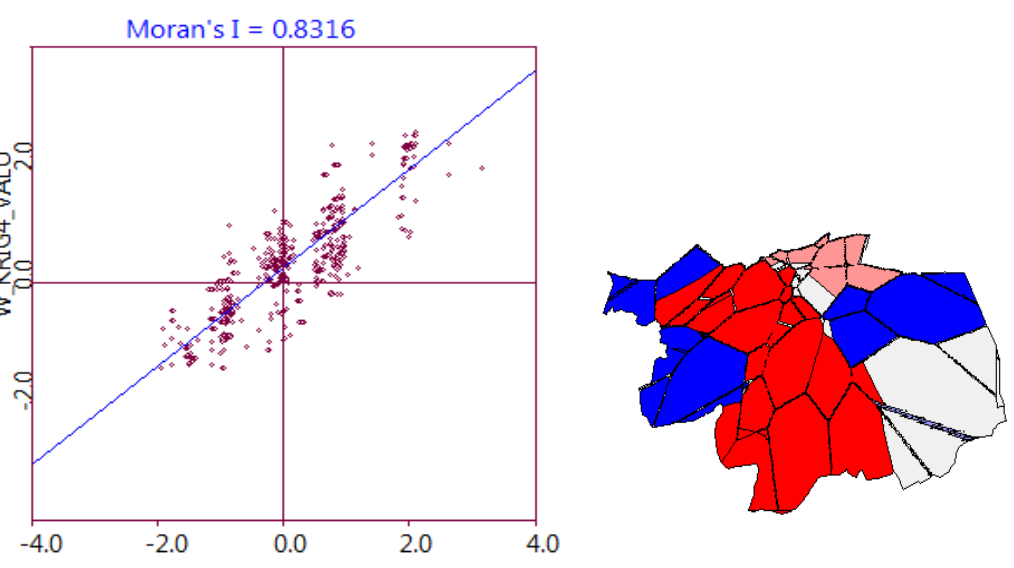

Moran's $I=0.9826$

(a)
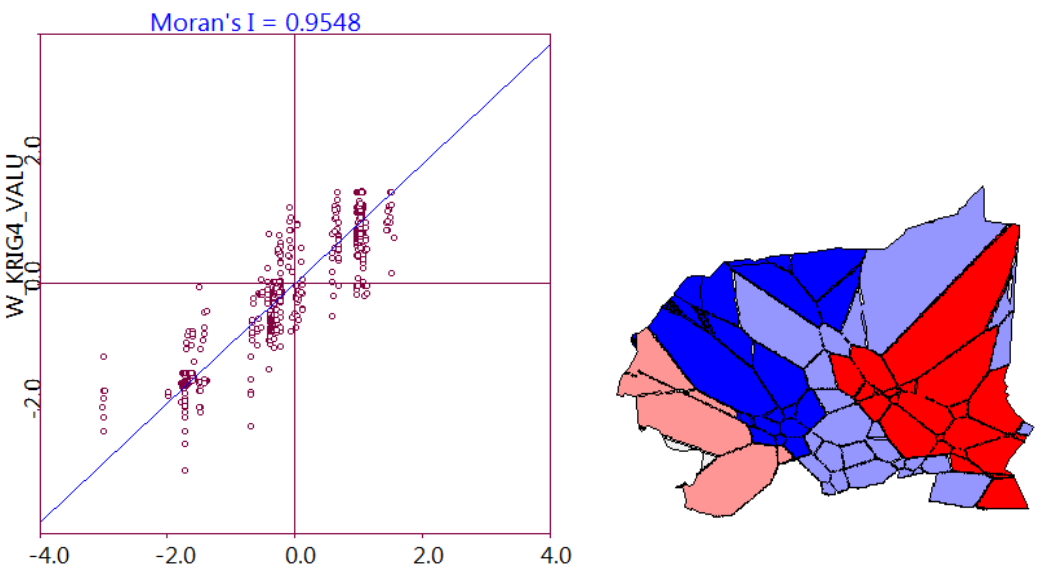

Moran's $I=0.8316$

Moran's $I=0.9548$

(c) 


\subsection{Spectral Extraction Analysis}

To investigate the spectral reflectance activities of the ground, digital numbers were extracted using the ENVI software (Environment for Visualizing Images) and the results are shown in Figure 10.

Figure 10. The spectral reflectance value and layer classes.

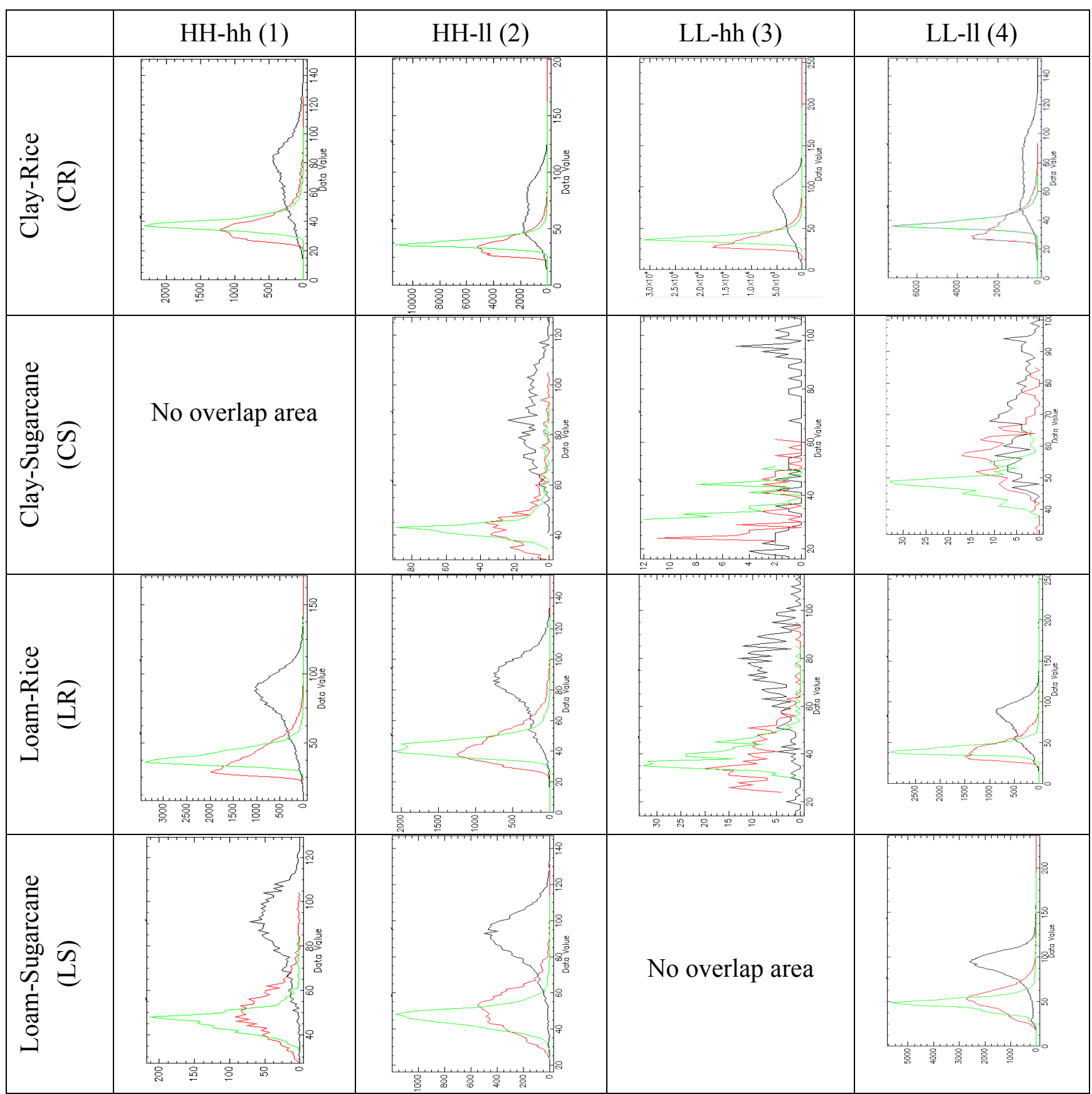

* DN value from LANDSAT5-TM extracted under the typical class; black $=$ band 4, red $=$ band 3 , green $=$ band 2 .

Figure 10 shows that the comparison of the statistical analysis results from an experiment by extracting the spectral reflectance from satellite data under different sampling areas. Chart of an experimental result for study the relation of nitrogen concentration in groundwater and the other layers 
which display by nitrate-nitrogen in $\mathrm{x}$-axis and average spectral reflectance in $\mathrm{y}$-axis. The result from the extraction is described as follows.

Clay-Rice (CR): The biggest amount of pixels from extraction showed a clustered pattern and covered $14.76 \%$ of the provincial area. The 1CR class gave the most uniform curve on the DN value of band 4 , meaning a very close stage of planting and land cover, while $2 \mathrm{CR}, 3 \mathrm{CR}$, and $4 \mathrm{CR}$ represented the double peak of value, that shows the different planting stages.

Clay-Sugarcane (CS): This random pattern covered $0.03 \%$ of the provincial area that was not suitable for sugarcane planting, due to the clay texture. The curve of the DN value was not overlaid on HH-hh. The rest was also not uniform, which shows that the maximum value of band 4 was represented on $2 \mathrm{CS}$, but the minimum in $3 \mathrm{CS}$.

Loam-Rice (LR): This class covered $3.18 \%$ of the provincial area. The 1LR and 2LR classes showed a unique curve of DN value from band 4, but 4LR showed a small peak around the value 50, representing the different stages of planting; the lower peak showed the water cover on the ground. The small amount of 3LR will not describe since the very small cover of area, 0.2 square kilometers.

Loam-Sugarcane (LS): This class covered $2.82 \%$ of the provincial area and most of the area was suitable for sugarcane. There was the small amount of DN value in 1LS and 2LS, which was the highest area of $\mathrm{NO}_{3}{ }^{-}-\mathrm{N}$. However, a continuous rising curve of band4was found in 4LS.

\section{Discussion}

The study approach followed spectral analysis of relationships between agricultural crops and nitrate concentrations in ground water by comparing two different spatial soil textures. The mean nitrate concentration of $1.0969 \mathrm{mg} / \mathrm{L}$ indicates that there is some human influence on nitrate concentrations in groundwater. Therefore, the results of this study should assist in the determination of significant sources of nitrate, helping in the estimation of fertilization practices to keep the levels within acceptable limits, lower than $1 \mathrm{mg} / \mathrm{L}$.

\subsection{Data Preparation}

\subsubsection{Landuse Class}

Since most of the land in the study site was located in irrigated areas, an individual crop calendar was present in the variety. The main crops in the study site are rice paddy and sugarcane. As seen from Figure 2, the adjacent crop area represents the different stages of planting in both rice paddy and sugarcane fields. These land uses frequently have nitrogen-based fertilizers applied to improve crop yield. Rice paddies are generally heavily fertilized, with a practical average of 40.63 ton $/ \mathrm{km}^{2}$ of 16-20-0 and 46-0-0 NPK, and sugarcane fertilizer is applied at a rate of is $46.88 \mathrm{ton} / \mathrm{km}^{2}$ [21]. Visual interpretation allows determination of the landuse cover: rice paddy field cover $29.4 \%\left(629.88 \mathrm{~km}^{2}\right)$ and sugarcane cover $10.4 \%\left(224.23 \mathrm{~km}^{2}\right)$ of whole study area. 


\subsubsection{Soil Texture}

Although there are nine units of soil covered in the area, the top soil presented only two types of texture. The clay texture covers $1,264.56 \mathrm{~km}^{2}$ and loam covers $740.84 \mathrm{~km}^{2}$, which are related with the rice paddy and sugarcane.

\subsubsection{Soil $\mathrm{pH}$}

Most of the area is found to be Class 4, which is the highest range of $\mathrm{pH}$ class in this study (pH 6.0-6.5) and it covered $862.49 \mathrm{~km}^{2}$, or $39.78 \%$ of the provincial area. The lower $\mathrm{pH}$ areas cover $554.83 \mathrm{~km}^{2}, 451.94 \mathrm{~km}^{2}$, and $125.32 \mathrm{~km}^{2}$ for $\mathrm{pH} 5.5,6.0$, and 4.5 , respectively.

\subsubsection{Groundwater Pond}

Groundwater monitoring stations were distributed in the whole study area (Figure 11). The maximum content of $\mathrm{NO}_{3}{ }^{-}-\mathrm{N}$ in groundwater is $6.1 \mathrm{mg} / \mathrm{L}$ from the station PD0102, located in the urban area. Mean value is 1.0969 , minimum is $0.45 \mathrm{mg} / \mathrm{L}$ (less than $0.9 \mathrm{mg} / \mathrm{L}$ according to the measurement by ion-selective electrode methods-Department of Groundwater Resources, Bangkok, Thailand, 2009, and the standard deviation is 1.1887 .

Figure 11. Location of groundwater monitoring stations showing nitrate concentration $(\mathrm{mg} / \mathrm{L})$.

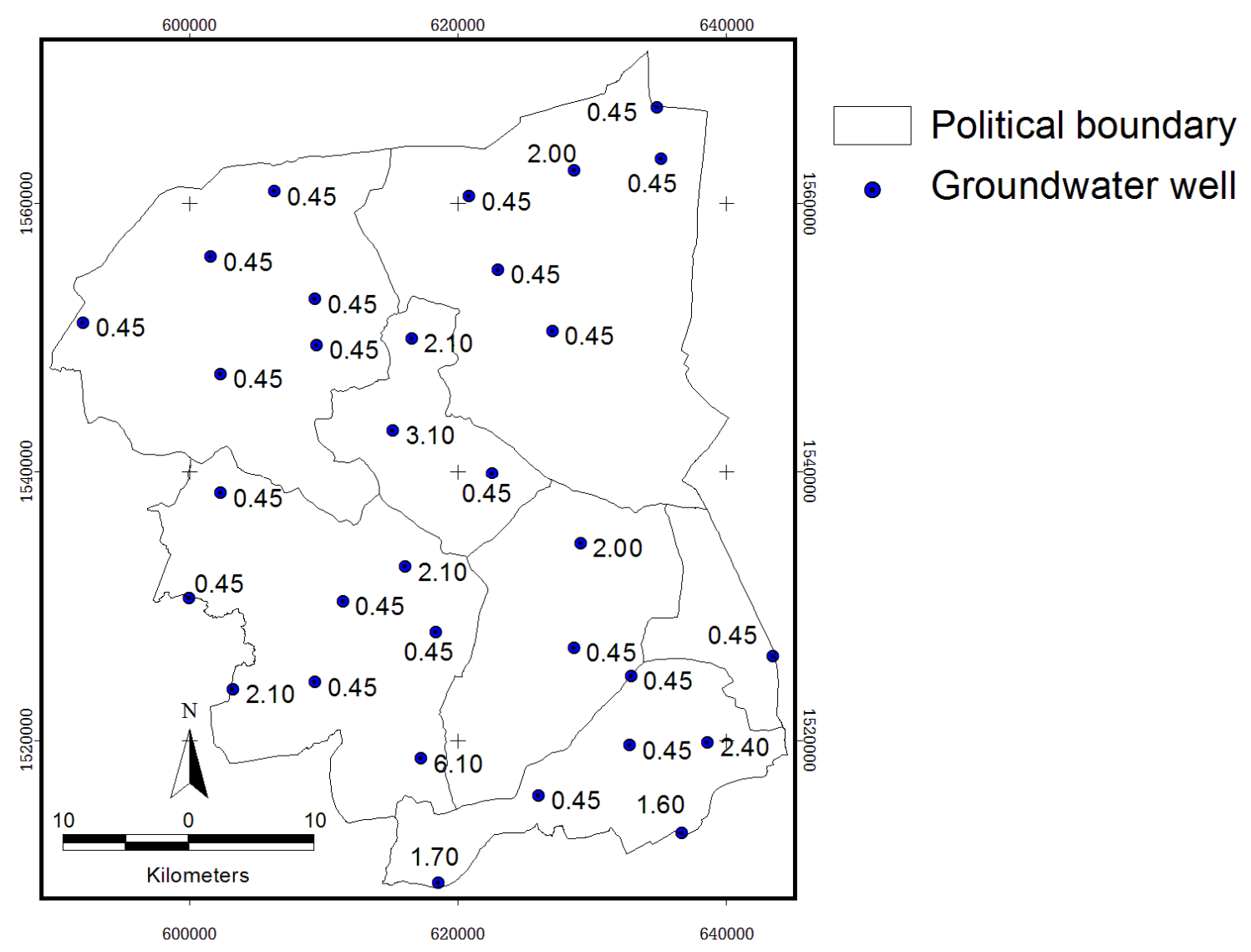




\section{2. $\mathrm{NO}_{3}{ }^{-}-\mathrm{N}$ Interpolation}

The results from Figure 7 show that several methods such as IDW1, spline3, spline4, krig1, krig3, and krig5 have a "bull's eye effect". Table 3 shows the observed group of means of the original measured $\mathrm{NO}_{3}{ }^{-}-\mathrm{N}$ content from DGR. The comparisons of mean value of nitrate concentrations among interpolation methods were assessed using the fixed-effect models analysis of variance (ANOVA). Each value point was extracted from the grid value under the point, including five check points. There were significant differences in nitrate concentrations among interpolation methods $(\mathrm{P}>0.05)$, as revealed by Duncan's Multiple Range Test (DMRT). The closest means from their residual when compared with the observed value was selected. Hence, Kriging with Gaussian criteria (KRIG4) was selected to be the most suitable result, as shown in Figure 8.

Table 3. The comparison of $\mathrm{NO}_{3}{ }^{-}-\mathrm{N}$ interpolation methods by mean of $\mathrm{NO}_{3}{ }^{-} \mathrm{N}$ concentration $(\mathrm{mg} / \mathrm{L})$.

\begin{tabular}{|l|c|c|}
\hline \multicolumn{1}{|c|}{ Treatment } & $\begin{array}{c}\text { Mean } \\
\left(\text { NO }_{3}^{-}{ }^{-}-\mathbf{~ i n ~} \mathbf{~ m g} / \mathbf{L}\right)\end{array}$ & $\Delta$ Observe * \\
\hline Observed (Sample $\left.\mathrm{NO}_{3}{ }^{-}{ }^{-} \mathrm{N}\right)$ & $\mathbf{1 . 0 9 6 9}$ & $\mathbf{0 . 0 0 0 0}$ \\
IDW1 & 1.0100 & 0.0869 \\
SPLINE1 & 1.0577 & 0.0392 \\
SPLINE2 & 1.0607 & 0.0362 \\
SPLINE3 & 1.0205 & 0.0764 \\
SPLINE4 & 1.0205 & 0.0764 \\
KRIG1 & 1.1030 & 0.0061 \\
KRIG2 & 1.1016 & 0.0047 \\
KRIG3 & 1.1032 & 0.0063 \\
KRIG4 & $\mathbf{1 . 1 0 1 3}$ & $\mathbf{0 . 0 0 4 4}$ \\
KRIG5 & 1.0505 & 0.0464 \\
KRIG6 & 1.0002 & 0.0967 \\
KRIG7 & 1.0065 & 0.0904 \\
\hline
\end{tabular}

* Calculated from the absolute difference of the observed value and each method.

\subsection{Spatial Autocorrelation Analysis}

The nitrate-nitrogen layer was classified by spatial autocorrelation analysis, which was compared by the mean of local and neighborhood of each other, and then classified into four classes, giving a high local and high neighborhood (HH), high local and low neighborhood (HL), low local and high neighborhood (LL), and low local and high neighborhood (LH). This was represented in the 1st, 2nd, 3rd, and 4th quadrant of the graph, respectively. Spatial autocorrelation analysis of $\mathrm{NO}_{3}{ }^{-} \mathrm{N}^{-}$from Kriging interpolation with Gaussian for whole study area as shown in the Figure 9(a), where the map is clustered into two big paths, up and down. However, the reclassifications of the clusters from separated High-High and Low-Low values in Figures 9(b) and (c) were shown to be more detailed and clustered, with Moran values of 0.8316 and 0.9548 , respectively. The local $\mathrm{NO}_{3}{ }^{-}-\mathrm{N}$ clusters from $\mathrm{HH}$ and LL were divided into four classes of nitrate. Soil $\mathrm{pH}$ and soil texture were reclassified into four and two classes, respectively, from a soil unit of the study area from soil map scale 1:100,000 and use 
only the top layer of each soil unit considering the root zone of the typical crops $(30 \mathrm{~cm})$. Landuse class focused on agricultural crop with high nitrate-nitrogen practice which gave two classes of layers. The multiple classes of layer which will be input for the intersection analysis and the number of data layer classes are shown in Table 4.

Table 4. Layer classes of data in this study.

\begin{tabular}{|c|c|c|c|c|}
\hline Layer & Class 1 & Class 2 & Class 3 & Class 4 \\
\hline Nitrate & HH-hh & HH-ll & LL-hh & LL-1l \\
Soil pH & 4.5 & 5.5 & 6.0 & 6.5 \\
Soil Texture & Loam & Clay & & \\
Landuse & Sugarcane & Paddy field & & \\
\hline
\end{tabular}

Although dissolved nitrogen will have the highest concentrations in soil with $\mathrm{pH} 6-8$, the scatter plot combination of $\mathrm{NO}_{3}{ }^{-} \mathrm{N}$ (Kriging-Gaussian) and soil $\mathrm{pH}$ (Figure 12), had no significant correlation between soil $\mathrm{pH}$ and $\mathrm{NO}_{3}{ }^{-}-\mathrm{N}$ content in groundwater (correlation slope $=-0.0125$ ). Hence, the soil $\mathrm{pH}$ class was not implemented in the intersection and spectral extraction process.

Figure 12. Effects of nitrate concentration in groundwater on the accuracy of the spatial interpolation methods (Kriging-Gaussian) compared in the average soil pH from soil unit.

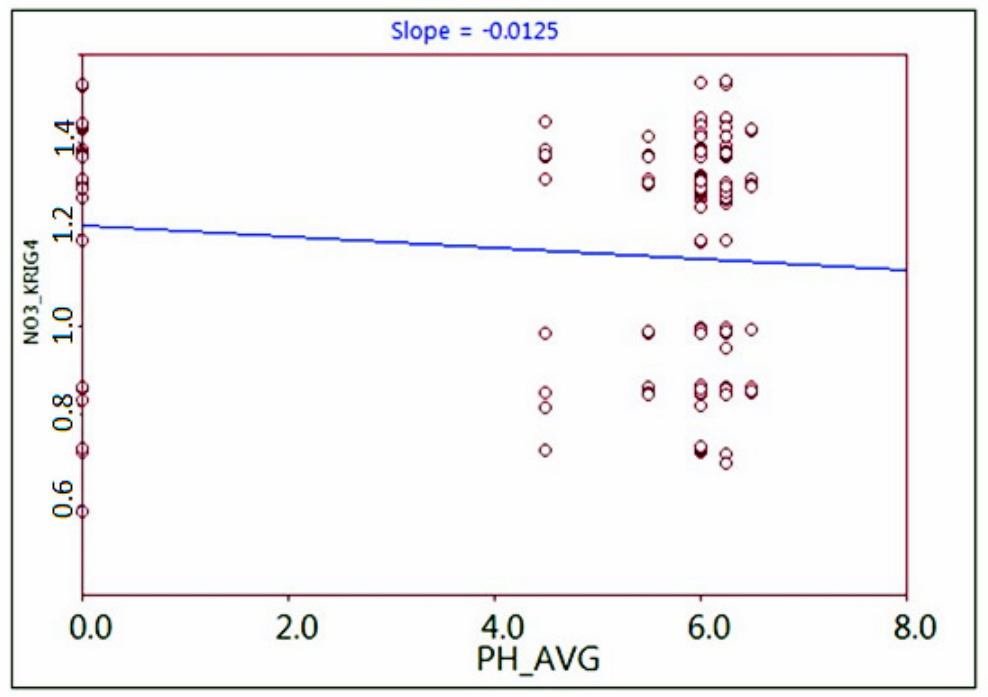

The average of difference method was used to compare an average of nitrate concentration from five points with the observed value. Kriging interpolation provided good results for all criteria, but the most suitable method was selected by the minimum difference from mean of an observed value.

The experiment of the combination of $\mathrm{NO}_{3}{ }^{-} \mathrm{N}$ and landuse crops as shown in Figure 13, where high nitrate-nitrogen content in groundwater of the study area were mostly found in the south to east of the study area, which is related to soil texture and landuse crops. However, the National Statistical Office has reported an increasing trend of fertilizer use in Thailand [29]. The use of nitrogen fertilizer (16-20-0 and 46-0-0, NPK) in the study area is also very high. The spectral reflectance extraction was processed from LANDSAT imagery data, which was separated into difference groups by the combination of $\mathrm{NO}_{3}{ }^{-} \mathrm{N}$ data with soil texture and crops. 
Figure 13. Combination of landuse crops and $\mathrm{NO}_{3}{ }^{-} \mathrm{N}$ concentration from Kiginging-Gaussian interpolation.

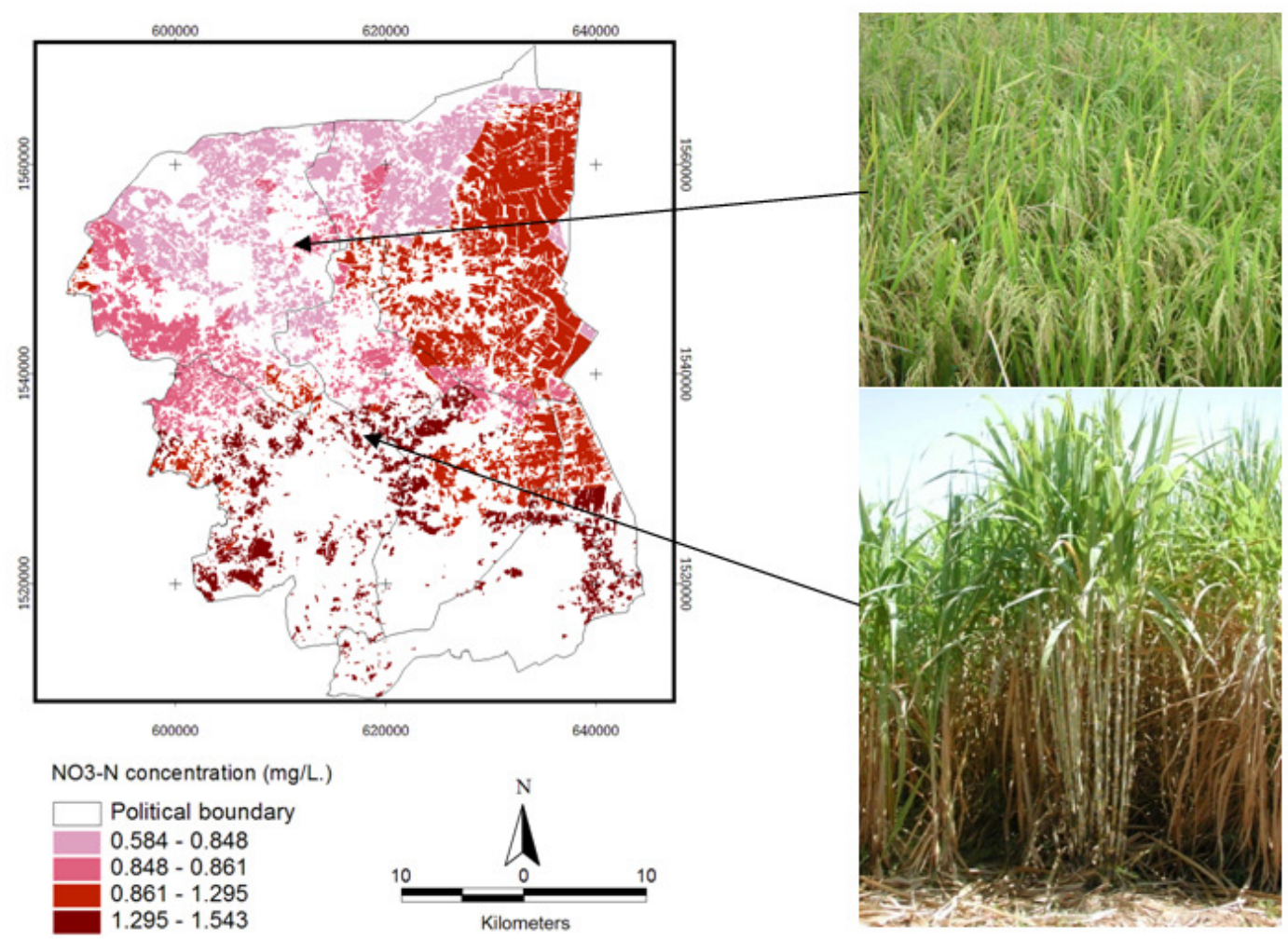

On the lower right photo is sugarcane, and upper right shows a rice paddy photo dated 20 May 2010. The black point of each crop is the point where the photo was shot and the color gradient represents the concentration of $\mathrm{NO}_{3}{ }^{-} \mathrm{N}$ from groundwater, interpolated from KRIG4, processed by the spatial overlay with landuse crops (rice paddy and sugarcane).

\subsection{Spectral Extraction Analysis}

Results of the extraction were processed in the ENVI software. Several layers were analyzed by spatial overlay analysis. The statistical information of each class is shown in Table 5. The total number of pixels of the LANDSAT imagery is 5,487,093 points; it was clipped with the provincial boundary, and the number of all pixels which were included in this extraction was 721,141 points. There are fourteen spectral results from the extraction, no overlay was present on Clay-Sugarcane/HH-hh (1CS) and Loam-Sugarcane/LL-hh (3LS), so those two results were cut off. The summary of the point numbers is shown in Figure 14.

The contrast comparison of the DN curve from Landsat band 4 found that the reflectance value from the rice paddy field which located on the high $\mathrm{NO}_{3}{ }^{-}-\mathrm{N}$ path $(\mathrm{HH}-\mathrm{hh})$ representing the unique and dominant peak of the curve, but in the low $\mathrm{NO}_{3}{ }^{-} \mathrm{N}$ path was representing the twice peak of the curve. For the sugarcane field, there was small covering area of sugarcane for high path but on the other hand the low path still represents the unique peak in the lowest path of $\mathrm{NO}_{3}{ }^{-}-\mathrm{N}$ concentration (4LS). However, the study found some irregular pattern of the curve in the classes of 2CS, 3CS, 3LR, and $4 \mathrm{CS}$. 
Table 5. Statistical information of classes from spatial overlay analysis.

\begin{tabular}{|c|c|c|c|c|c|c|}
\hline \multirow[t]{2}{*}{ No. } & \multirow[t]{2}{*}{ Class } & \multicolumn{4}{|c|}{$\begin{array}{c}\mathrm{NO}_{3}^{-}-\mathrm{N}(\mathrm{mg} / \mathrm{L}) \\
\text { from Kriging-Gaussian }\end{array}$} & \multirow[t]{2}{*}{$\begin{array}{c}\text { Area } \\
(\%)\end{array}$} \\
\hline & & Min & Max & Mean & SD & \\
\hline 1 & Study area & 0.58 & 1.54 & 1.07 & 0.26 & 100.00 \\
\hline 2 & $1 \mathrm{CR}$ & 1.30 & 1.54 & 1.44 & 0.06 & 0.63 \\
\hline 3 & $1 \mathrm{CS}$ & \multicolumn{4}{|c|}{ No overlap area } & 0.00 \\
\hline 4 & $1 \mathrm{LR}$ & 1.25 & 1.47 & 1.40 & 0.05 & 1.17 \\
\hline 5 & $1 \mathrm{LS}$ & 1.26 & 1.45 & 1.35 & 0.05 & 0.05 \\
\hline 6 & $2 \mathrm{CR}$ & 1.27 & 1.38 & 1.27 & 0.00 & 2.98 \\
\hline 7 & $2 \mathrm{CS}$ & 1.25 & 1.31 & 1.31 & 0.01 & 0.02 \\
\hline 8 & $2 \mathrm{LR}$ & 1.18 & 1.37 & 1.28 & 0.05 & 0.84 \\
\hline 9 & $2 \mathrm{LS}$ & 1.18 & 1.32 & 1.24 & 0.06 & 0.40 \\
\hline 10 & $3 \mathrm{CR}$ & 0.98 & 0.98 & 0.98 & 0.00 & 9.58 \\
\hline 11 & $3 \mathrm{CS}$ & 0.98 & 0.98 & 0.98 & 0.00 & 0.00 \\
\hline 12 & $3 \mathrm{LR}$ & 0.98 & 0.98 & 0.98 & 0.00 & 0.01 \\
\hline 13 & $3 \mathrm{LS}$ & \multicolumn{4}{|c|}{ No overlap area } & 0.00 \\
\hline 14 & $4 \mathrm{CR}$ & 0.70 & 1.46 & 0.79 & 0.21 & 1.57 \\
\hline 15 & $4 \mathrm{CS}$ & 0.69 & 0.73 & 0.72 & 0.01 & 0.01 \\
\hline 16 & $4 \mathrm{LR}$ & 0.69 & 0.86 & 0.72 & 0.01 & 1.16 \\
\hline 17 & $4 \mathrm{LS}$ & 0.69 & 1.31 & 0.79 & 0.20 & 2.36 \\
\hline \multicolumn{6}{|c|}{ Total } & 20.79 \\
\hline
\end{tabular}

Figure 14. Pixel distribution from spectral extraction analysis.

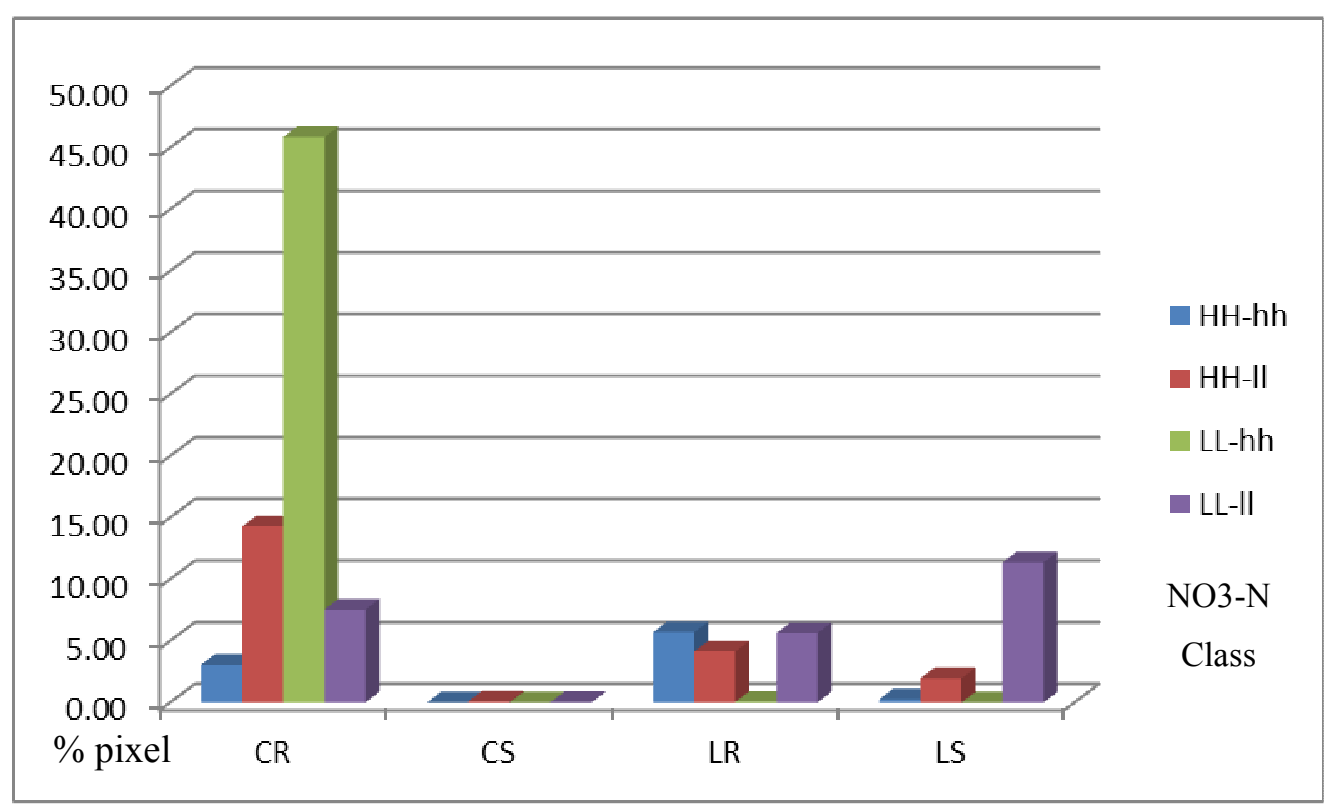

\section{Conclusions}

The nitrate was classified into four classes by spatial autocorrelation analysis (Moran's I and Local Moran statistics; LISA), by a means comparison. The cluster map legend contains five categories: Not significant (Areas that are not significant at a default pseudo significance level of 0.05), High-High (High values surrounded by high values), Low-Low (Low values surrounded by low values), 
Low-High (Low values surrounded by high values), and High-Low (High values surrounded by low values). There were 2 classes of the global clustered of $\mathrm{NO}_{3}{ }^{-} \mathrm{N}$ with values of Moran's I of 0.8316 $(\mathrm{p}=0.05)$ for $\mathrm{HH}$, and $\mathrm{I}=0.9548(\mathrm{p}=0.01)$. However, the local Moran's statistics shown HH-hh $(\mathrm{I}=0.8182, \mathrm{p}<0.01)$, HH-ll $(\mathrm{I}=0.3486, \mathrm{p}<0.01)$, LL-hh $(\mathrm{I}=0.6534, \mathrm{p}=0.01)$, and LL-LL $(\mathrm{I}=0.4065, \mathrm{p}<0.5)$. The effect of soil texture on nitrate-nitrogen content in groundwater was directly observed by its reflectance values through remote sensing. It was found that $\mathrm{NO}_{3}{ }^{-} \mathrm{N}$ measured through the loam in sugarcane $(I=0.0054, p<0.05)$ was lower than clay represented in paddy $(I=0.0305$, $\mathrm{p}<0.05)$. This had a significant negative impact on the assumption, the quantity of nitrogen leached into groundwater through loam was higher than through clay.

According to the research [2] and local statistical data [19], farmers always apply excess fertilizer to paddy fields. This is a main reason for the higher quantity of $\mathrm{NO}_{3}{ }^{-} \mathrm{N}$ found in clay than in loam in this study. This case might be an exceptional study in terms of the quantity of fertilizers applied to agricultural fields. There was high level of $\mathrm{NO}_{3}{ }^{-}-\mathrm{N}$ contaminants in urban areas, showing that there are other sources of contaminants. Therefore, there is a need to investigate the combined and multiple sources of contamination in urban areas that can cause hazard to urban populations.

\section{Acknowledgments}

We would like to express our sincere gratitude to Silpakorn University, Thailand for providing financial support to this research. We are also extremely grateful to the Department of Groundwater Resources (DGR) for data and information on site survey.

\section{Conflict of Interest}

The authors declare no conflict of interest.

\section{References}

1. World Health Organization. Guidelines for Drinking-water Quality, 3rd ed.; World Health Organization: Geneva, Switzerland, 2004; Volume 1, Recommendations.

2. Tirado, R.; Englande, A.J.; Promakasikorn, L.; Novotny, V. Technical Note 03/2008; Greenpeace Research Laboratories: Exeter, UK, 2008.

3. Federal Register. National interim primary drinking water standards. Federal Register 40:59, 566588, 1975.

4. Gaines, T.P.; Gaines, S.T. Soil texture effect on nitrate leaching in soil percolates. Commun. Soil Sci. Plant Anal. 1994, 25, 2561-2570.

5. Alley, W.M. Regional Ground Water Quality; Van Nostrand Reinhold: New York, NY, USA, 1993; p. 635.

6. Reddy, A.G.S.; Kumar, K.N.; Rao, S.D.; Rao, S.S. Assessment of nitrate contamination due to groundwater pollution in north eastern part of Anantapur District, A.P. India. Environ. Monit. Assess. 2009, 148, 463-476.

7. Weston, D.; Seelig, B. Managing Nitrogen Fertilizer to Prevent Groundwater Contamination, Extension Bulletin No. 64; North Dakota State University: Fargo, ND, USA, 1994. 
8. Cisse, I.A.; Mao, X. Nitrate: Health effect in drinking water and management for water quality. Environ. Res. 2008, 2, 311-316.

9. Vogt, C.; Cotruvo, J. Drinking water standards: Their derivation and meaning. In Rural Groundwater Contamination; D’Itri, F.M., Wolfson, L.G., Eds.; Lewis Publishers: Chelsea, MI, USA, 1987; pp. 213-223.

10. Rail, C.D. Groundwater Contamination: Sources, Control, and Preventive Measures; Technomic Publishing Company, Inc.: Lancaster, PA, USA, 1989; p. 139.

11. Pathak, B.K.; Iida, T.; Kazama, F.; Jaisi, D.P. Nitrogen contribution to the river basin from tropical paddy field in the central Thailand. In Proceedings of 9th International River Symposium, Brisbane, Australia, 4-7 September 2006.

12. Hassink, J. Effects of soil texture and grassland management on soil organic $\mathrm{C}$ and $\mathrm{N}$ and rates of $\mathrm{C}$ and N mineralization. Soil Biol. Biochem. 1994, 26, 1221-1231.

13. Brady, N.C. The Nature and Properties of Soil, 8th ed.; MacMillan Publishing Co. Inc.: New York, NY, USA, 1974; p. 4070.

14. Akram, H.A.H. The impact of soil texture on nitrates leaching into groundwater in the North Governorate, Gaza Strip. J. Soc. Sci. 2010, 38, 1-37.

15. Jackson, T.J. Remote sensing of soil moisture: implications for groundwater recharge. Hydrogeology 2002, 10, 40-51.

16. Waters, P.; Greenbaum, P.; Smart, L.; Osmaston, H. Applications of remote sensing to groundwater hydrology. Remote Sens. Rev. 1990, 4, 223-264.

17. Engman, E.T.; Gurney, R.J. Remote Sensing in Hydrology; Chapman and Hall: London, UK, $1991 ;$ p. 225.

18. Meijerink, A.M.J. Groundwater. In Remote Sensing in Hydrology and Water Management; Schultz, G.A., Engman, E.T., Eds.; Springer: Berlin, Germany, 2000; pp. 305-325.

19. National Statistical Office. The 2008 Agriculture Intercensal Survey, Region: Central; National Statistical Office Publications: Bangkok, Thailand, 2008.

20. Wakefield, J.C.; Kelsall, J.E.; Morris, S.E. Clustering, cluster detection, and spatial variation in risk. In Spatial Epidemiology; Elliott, P., Wakefield, J., Best, N., Briggs, D., Eds.; Oxford University Press: Oxford, UK, 2000; pp. 128-152.

21. Anselin, L. GeoDa 0.9 User's Guide; Spatial Analysis Laboratory, University of Illinois: Urbana-Champaign: Urbana, IL, USA, 2003.

22. Kriging Interpolation Extension 2.01. ESRI Inc: Redlands, CA, USA, 2010; Available online: http://arcscripts.esri.com/details.asp?dbid=10652 (accessed on 17 May 2011).

23. Pick, T. Assessing the risk of ground water contamination from open lot management on Animal Feeding Operations (AFOs). Ecological Sciences-Environment Technical Note Number MT-3. Natural Resources Conservation Service: Bozeman, MT, USA, 2006; Available online: http://www.mt.nrcs.usda.gov/technical/ecs/environment/technotes/envmt3/ (accessed on 3 May 2011).

24. Land Development Department (LDD). Soil Map of Nakhon Pathom 1:50,000; Ministry of Agriculture and Cooperatives: Bangkok, Thailand, 2007.

25. Food and Agriculture Organization of the United Nations (FAO), Land Development Department (LDD). Soil Interpretation Hand Book for Thailand; Ministry of Agriculture and Cooperatives: Bangkok, Thailand, 1973; p. 178. 
26. Basin Development Plan Unit. Thai National Mekong Committee. Ministry of Natural Resources and Environment. Sub-area Study and Analysis 5T Sub-Area; Thai National Mekong Committee: Bangkok, Thailand, 2004.

27. Newman, J.A.; Bergelson, J.; Grafen, A. Blocking factors and hypothesis tests in ecology: Is your statistics text wrong? Ecology 1997, 78, 1312-1320.

28. McDonald, J.H. Handbook of Biological Statistics, 2nd ed.; Sparky House Publishing: Baltimore, MD, USA, 2009; pp. 127-129.

29. National Statistical Office. The 2008 Agriculture Intercensal Survey, Whole Kingdom; National Statistical Office Publications: Bangkok, Thailand, 2008.

(C) 2011 by the authors; licensee MDPI, Basel, Switzerland. This article is an open access article distributed under the terms and conditions of the Creative Commons Attribution license (http://creativecommons.org/licenses/by/3.0/). 